\title{
Mesoblast Limited
}

National Cancer Institute

\section{Source}

National Cancer Institute. Mesoblast Limited. NCI Thesaurus. Code C134824.

An Australian biotechnology company that is developing a proprietary technology

platform based on allogeneic mesenchymal lineage adult stem cells (MLCs) to target inflammatory ailments, cardiovascular disease, and back pain. 